\title{
Aesthetic Values in Science
}

\author{
Milena Ivanova \\ Forthcoming in Philosophy Compass \\ mail@milenaivanova.co.uk | milenaivanova.co.uk
}

\section{Introduction}

Scientists often use aesthetic values in the evaluation and choice of theories. Aesthetic values are not only regarded as leading to practically more useful theories, but are often taken to be indicators of the truth of a theory. This paper explores what aesthetic considerations influence scientists' reasoning, how such aesthetic values relate to the utility of a scientific theory, and how one can justify the epistemic role for such values. The paper examines ways in which the link between beauty and truth can be defended, the challenges facing such accounts, and explores alternative epistemic roles for aesthetic values in scientific practice.

\section{Aesthetic Judgment in Science}

Aesthetic judgments appear to be part of scientific theorising. Scientists often praise hypotheses, proofs, experiments, and theories on their aesthetic merit and furthermore place epistemic import on such merit. Some scientists claim that the beauty of scientific theories is a driving force of scientific research, suggesting that the aim of science is to find beauty in nature. The French mathematician Henri Poincaré, for instance, claimed that an aesthetically pleasing theory generates in the scientist an aesthetic response for which the intellect has full appreciation and actively searches. In Science and Method, Poincaré argues that the reason scientists study nature is to experience an aesthetic response by appreciating how diverse phenomena are harmoniously accommodated by a theory. He claims that "[t]he scientist does not study nature because it is useful 
to do so. He studies it because he takes pleasure in it, and he takes pleasure in it because it is beautiful. I am not speaking, of course, of the beauty which strikes the senses [...] What I mean is that more intimate beauty which comes from the harmonious order of its parts, and which pure intelligence can grasp (2001, 368).

Aside from this motivational role, beauty is often taken to have a heuristic role in scientific activities. Aesthetic values are often appealed to in order to resolve the underdetermination of theory by the data, when empirical evidence is insufficient to choose between competing theories (Duhem (1954)). In such situations, aesthetic values aid theory choice, leading to the adoption of one empirically adequate theory over another. Ernst Mach's (1919) 'economy of thought' principle is one such methodological application of simplicity as a heuristic guide to choosing between empirically equivalent theories.

In addition to its heuristic and motivational roles, beauty is often taken to stand in a special epistemic relationship to truth. Many scientists and philosophers have held that a beautiful theory is more likely to be true. Paul Dirac famously claimed that "one has a great confidence in [a] theory arising from its great beauty, quite independently of its detailed successes" (Dirac 1980, 40). Dirac takes beauty to be linked to truth, such that we can be confident in the truth of a beautiful theory independently of its empirical adequacy. He claims that "[o]ne has an overpowering belief that [the theory's] foundations must be correct quite independently of its agreement with observation" (ibid.). Werner Heisenberg also defended the intrinsic relationship between truth and beauty: "[i]f nature leads us to mathematical forms of great simplicity and beauty we cannot help thinking that they are "true", that they reveal a genuine feature of nature" (Heisenberg 1971, p. 68). James Watson (1968) suggests that what convinced Rosalind Franklin, who had already considered the double helix structure of DNA but believed some of the x-ray pictures she had produced gave evidence against it, was the fact that the double helix structure of DNA was too beautiful not to be true (Watson 1968, p. 124). The Nobel laureate Subrahmanyan Chandrasekhar similarly held that it is reasonable to believe that "a theory developed by a scientist, with an exceptionally well- 
developed aesthetic sensibility, can turn out to be true even if, at the time of its formulation, it appeared not to be so" $(1987,64)$.

Aesthetics has come into science not only because scientists often employ aesthetic values in their decision-making, but furthermore, because sometimes the very product of science or the process of discovery has been regarded as a work of art. Some scientists regard the product of their intellectual activities, whether scientific theories, models, or mathematical proofs, as works of art. For example, the French physicist Pierre Duhem claimed that "it is impossible to follow the march of one of the great theories of physics, to see it unroll majestically its regular deductions starting from initial hypotheses, to see its consequences represent a multitude of experimental laws down to the small detail, without being charmed by the beauty of such a construction, without feeling keenly that such a creation of the human mind is truly a work of art" (Duhem 1954, 24). Furthermore, Ernest Rutherford claimed that theories can be conceived as artistic productions: "a strong claim can be made that the process of scientific discovery may be regarded as a form of art. This is best seen in the theoretical aspect of Physical Science. The mathematical theorist builds up on certain assumptions and according to well understood logical rules, step by step, a stately edifice, whilst imaginative power brings out clearly the hidden relations between its parts. A well constructed theory is in some respects undoubtedly an artistic production." [quoted in McAllister 1996, 14]

Apart from appraising theories on their aesthetic appeal, scientists very often discuss the role of their aesthetic sensibility and their ability to select useful theories based on this sensibility. Poincaré, for example, argues that when a mathematician is generating potential hypotheses and proofs, the aesthetic sensibility "plays the part of the delicate sieve" which checks the result blindly generated by the mind and selects only the most elegant and beautiful combinations produced $(2001,397)$. He links the aesthetic sensibility with the utility of the proof, claiming that "[t]he useful combinations are precisely the most beautiful" (ibid.) ${ }^{1}$. Similarly, John von Neumann held that "a

\footnotetext{
1 Poincaré's interesting account of creativity in mathematics and science is analysed in Livingston (2009).
} 
mathematician's criteria of success, and also those of truth, are mainly aesthetic" (von Neumann 1961, 2062). When discussing the problem of underdetermination, Duhem employs a concept of 'good sense' in order to explain how scientists come to an agreement about the aesthetic properties of theories. Just like David Hume, Duhem appeals to the good sense of scientists who can appreciate the aesthetic properties of theories in an unbiased and impartial way and reach a conclusive choice (Duhem 1954, 218). For Duhem, it is good sense that ensures that despite the subjective nature of aesthetic judgments, scientists with good sense can come to an objective agreement about the aesthetic merit of theories (Stump (2007), Ivanova (2010, 2014, 2015)).

Aesthetics has come into philosophy of science also with the recent focus on the concept of scientific representation. The subject of scientific representation and its relation to representation in art has generated considerable debate in the recent literature, especially since the rise of the semantic approach to scientific theories (Chakravartty (2007), French (2003, 2014), Frigg and Hunter (2010) van Fraassen (2008)). Some have even taken science to be a representational art. Kivy (1991), for example, argues that appreciating a theory epistemically and aesthetically is interrelated insofar as one cannot appreciate the theory's representational success without appreciating its aesthetic value as well.

While plenty of scientists attribute a genuine epistemic role to aesthetic judgments, scepticism has also developed towards this claim. An alternative view is that aesthetic language used by scientists is reducible to, or a manifestation of, statements about the empirical adequacy of a theory. On this account, when a scientist is attributing aesthetic value to a theory, they are simply using a different language to state that the theory is empirically adequate. To question any substantial role for aesthetic judgements in science one can appeal to the traditional distinction between the context of discovery and the context of justification (originally drawn by Reichenbach (1947)) and claim that aesthetic factors, understood as subjective factors, are only relevant in the context of discovery. The context of justification, on the other hand, is seen as a rational process involving only objective factors, and so aesthetic values have 
no place in this context. This distinction, however, has been questioned on the grounds that aesthetic considerations figure in both contexts. As Cellucci (2014) argues, beauty plays an important role in both contexts, since it guides the selection of hypotheses in the development of a theory. A further problem for reducing aesthetic language to statements about empirical adequacy is that aesthetic factors are often the only factors available in decision-making, such as when a theory has yet to obtain empirical support. Aesthetic values often drive the preference of one theory over another in the case of underdetermination, and moreover they are appealed to in order to provide evidential support in cases where empirical confirmation for a theory has not been obtained. This is notable in the case of string theory and cosmological theories, where appeal to aesthetic considerations in support of a theory is crucial in the absence of empirical data.

Scepticism towards the status of aesthetic judgments in science has also been developed on the grounds that it is difficult to define exactly what constitutes an aesthetic response. McAllister (1996) appeals to the notion of aptness in conjunction with taking scientists' aesthetic claims literally, although this idea has been subject to criticism (Todd (2008), Montano (2014)). Is it argued that without a satisfactory account defining what constitutes an aesthetic response, we have no grounds to infer that the claims scientists make about the beauty of theories are of a genuinely aesthetic nature. Todd (2008) argues that without such conditions, it is difficult to see why the properties generally regarded as aesthetic are anything but epistemic in nature.

An interesting insight into the nature of aesthetic claims in science comes from recent studies in neuropsychology that demonstrate the appreciation of mathematical equations to correspond to the same brain activity as aesthetic appreciation of music and art. Using functional magnetic resonance imaging to detect brain activity, Zeki et al. (2014) show that the same areas of the brain are active when a mathematician is exposed to equations they have previously described as beautiful as when they are appreciating pieces of art and music. In the study Zeki et al. report that "the experience of mathematical beauty correlates with activity in the same brain area [medial orbito-frontal cortex] 
active during the experience of visual, musical, and moral beauty" (Zeki et al. 2014 , 8). While these studies do not directly address the sceptical worries discussed above, they do give important insight into the mechanisms that allow us to experience beauty, and show that scientists are indeed reporting an aesthetic experience when praising theories or proofs as beautiful. In the next sections, we engage with the concept of beauty employed in science (sec. 3), discuss how scientists come to regard some features of a theory as aesthetically appealing (sec. 4), and address the role and justification of aesthetic considerations in scientific reasoning (sec. 5).

\section{Beauty and Aesthetic Values}

When it comes to the concept of beauty, one question that has traditionally puzzled philosophers is whether beauty is an objective property of theories or whether it is projected onto theories by us. Objectivists argue that works of art deemed aesthetically valuable in the past, such as Leonardo da Vinci's paintings and Homer's poems, continue to be valued today, making aesthetic judgements bear eternal validity rather than being subject to change and fashion. Projectivists, on the other hand, argue that beauty is a dynamic concept, and what is considered beautiful today might not be considered beautiful tomorrow. Some scientists claim that even if the concept of beauty is allowed to change in the arts, aesthetic judgments in science have objective and universal validity (Zee (1999), Greene (1999) and Thuan (2001)). These authors claim that values such as simplicity, symmetry, and elegance are not subject to revision in science and are universally recognised as beautiful. Similarly, Dirac claimed that while aesthetic judgments in art very much depend upon contingent factors such as culture and upbringing, beauty in mathematics exhibits objective and universal validity (Dyson 1987).

While some scientists claim that the concept of beauty cannot be analysed, many give an insight into the way they understand the concept, by reducing it to certain aesthetic properties like simplicity, symmetry, harmony or unity (the concept of beauty is systematically analysed in Engler (2002), 
McAllister (1996), Breitenbach (2013), de Regt (2002), Gaut and Lopez (2013), Cellucci (2014)). One question that arises is whether these aesthetic values can be regarded as universally accepted. Some claim that aesthetic properties associated with beauty can differ in time and can also be understood differently across the disciplines or even within the same discipline by different groups of scientists. As Duhem (1954) argues, aesthetic values such as simplicity and elegance "are essentially subjective, contingent, and variable with time, with schools, and with persons" (p. 288). McAllister shares this conviction, pointing to numerous examples from the history of science where the forms of aesthetic appreciation changed through theory transitions. He claims that visualisation, for example, stopped being aesthetically valued with the development of quantum mechanics, while the desire for symmetry became especially important after the advent of relativity theory (McAllister 1996). McAllister defends a 'dynamic' conception of beauty, according to which aesthetic properties associated with beauty can change and be replaced. Furthermore, McAllister holds that even at a particular time scientists have the freedom to understand each property in different ways.

A further worry for the objectivist account comes from the observation that aesthetic properties associated with beauty might differ across the fields. One insight comes from biology, where complexity and irregularity are often praised and regarded as more desirable than simplicity and regularity. As the biologist Stephen Jay Gould argued, we can find beauty in simple mathematical principles as well as in unrepeatable complex contingencies. Whereas the idea of complexity and irregularity being aesthetically valuable stems from the background assumption that complexity in the biological world increases with time, this claim has recently been questioned by O'Malley, Wideman and RuizTrillo (2016) who argue that simplification, understood as the reduction of biological complexity at different levels, occurs across the tree of life, and is responsible for diversification through the reduction of parts and even losses of hierarchical complexity.

The latter worry brings to attention the importance of the context in which aesthetic judgments are made. For example, different aesthetic values 
can be desirable in the context of (1) developing a theory and (2) studying phenomena. Desire for complexity in the phenomena can indeed be found in physics, where symmetry breaking is considered beautiful exactly because it helps to further our knowledge. Desire for theories with a high number of symmetries, however, remains something of an imperative in modern physics widely adopted in the discipline.

Lastly, note that many scientific objects might be aesthetically praised. Although when discussing the concept of truth or utility it is standard to focus on the aesthetic properties of scientific theories, it is important to note that scientists praise many objects as aesthetically valuable; e.g. mathematical proofs, scientific discoveries, scientific experiments, observations and models. The concept of mathematical beauty, and the question of how mathematics applies to physics, has received systematic attention in the literature (Cellucci (2015), Engler (1990), McAllister (2005), Montano (2013)). Systematic analysis has also been given to the aesthetic value of experiments in physics and biology and their epistemic role (Holmes (1996, 2001), Parsons and Reuger (2000), Reuger (1997)).

\section{Truth and Beauty}

Aesthetic judgements are widely employed in scientific practise, but can they play a substantial epistemic role? Can we justify the claim, so often made by scientists, that beauty is indicative of truth? According to James McAllister (1996), aesthetic values can justify one's confidence in a theory even if the theory has not received sufficient empirical support. The reliability of such values is supported by appealing to the established aesthetic canon, based on the aesthetic properties of the most empirically successful theories of the past. The argument relies on a mechanism known in the psychology literature as the 'exposure effect'. Studies performed on subjects have found that an agent's aesthetic preference towards an object tends to increase the more the agent is exposed to the object (Cutting (2003)). McAllister claims that scientists learn from their experience, by habituation or exposure, what aesthetic values have 
been associated with successful theories, and they project an expectation that such values will continue to be properties of successful theories, taking such theories to be true. The justification for the link between beauty and truth is based on an aesthetic induction - we infer that a theory conforming to the established aesthetic cannon is more likely to be empirically successful or true. ${ }^{2}$

McAllister offers a reductionist account of beauty by analysing beauty in terms of simplicity, symmetry, harmony, visualisation and elegance. He employs a dynamical notion of beauty in order to allow for aesthetic values to change with scientific progress. McAllister takes aesthetic discontinuities to occur in theory transitions, and claims that what drives the revision of an aesthetic canon is ultimately the empirical success of the superseding theory. An analogy is drawn with the history of architecture, where we find similar increase of aesthetic appreciation of certain structures only after the utility of the new materials used for their design has been fully appreciated and utilised. Notable examples of architectural icons that initially received negative aesthetic praise include the Eiffel Tower and St Pancras Station, whose aesthetic value increased with the appreciation of their practical utility. One might object to the claim that aesthetic values can be useful predictors of success by appealing to examples of aesthetically appealing theories that turned out to be false (e.g. Newtonian mechanics; Kaluza-Klein theory), or contemporary empirically successful theories that are not widely considered to have strong aesthetic merit (e.g. the Standard Model of particle physics).

While a dynamic conception of beauty aims at blocking worries about aesthetic discontinuities in theory change, some argue that certain aesthetic values have been persistently desired and associated with the ideal end of science, independently of whether they have been continuously exemplified by empirically successful theories of the past. For instance, Montano (2014) argues that values such as simplicity and unity have been 'historical constants', not subjected to change or fashion. It seems plausible that certain aesthetic values have remained highly desirable despite not being instantiated by highly

${ }^{2} \mathrm{~A}$ further defence of the link between beauty and truth is given in Kuipers (2002) and Montano (2014). 
successful contemporary theories. Also, contrary to the exposure effect, some properties have failed to gain aesthetic appeal despite being instantiated by highly successful theories. For example, exposure to the Standard Model's enormous empirical success, or the success of computer-assisted proofs in mathematics, has not resulted in an increased appreciation of complexity over simplicity in scientific theories. The fact that scientists aim to develop grand unifying theories shows that unity and simplicity continue to be highly appreciated independently of the limited successes of contemporary unificationist projects.

The claim that we learn to appreciate certain aesthetic properties of successful theories by habituation is also challenged by recent studies on the exposure effect in aesthetics that, I suggest, shed doubt on the claim that exposure is sufficient for an agent's increased aesthetic appreciation. Consider the recent studies on the exposure effect in art conducted by Meskin, Phelan, Moore and Kieran (2013). These studies show that exposure to 'bad' art does not correlate with increase in subjects' aesthetic appreciation, suggesting that something over and above exposure must be responsible for subject's aesthetic responses to art pieces. By considering these results in the context of science, we have grounds to challenge the idea that exposure and habituation are responsible or sufficient for scientists' appreciation of the aesthetic values of scientific theories. This problem calls for the further examination of the exposure effect in order to understand why some aesthetic values, such as simplicity and unity, remain the ultimate aims of science independently of whether scientists have had systematic exposure to successful theories exemplifying these values.

\section{Aesthetic Values and Understanding}

Further to the relationship between aesthetic values and truth, some philosophers have explored an alternative epistemic role for aesthetic values in science. Rather than taking aesthetic values to be indicators of the truth of a theory, aesthetic values can be taken to be indicative of scientific 
understanding. The unificationist project, initially developed by Friedman (1974) and Kitcher (1981) offered an analysis of how unification can lead to understanding. Some philosophers are now exploring whether the aesthetic responses of scientists are simply an aspect of gaining understanding, and how aesthetic experience and experience of understanding are related. Elgin (1991) also draws important analogies between understanding in art and science.

Recent accounts of understanding maintain that understanding differs from knowing; it involves an ability to grasp how the facts fit together ${ }^{3}$. As Thomas Kuhn (1970) notes, there is a difference between reciting relevant laws and principles, and understanding how to apply these laws and principles (p. 23). The ability to see how certain truths relate to each other and apply them to different contexts is considered an essential element of understanding. Truth, however, on this account, is not a requirement for understanding (Elgin (2009), Mizrahi (2012), de Regt (2004), Toon (2015), Strevens (2013)). As Henk de Regt (2015) argues, if truth is a necessary condition for understanding, we are led to the claim that past scientists have lacked understanding of phenomena for which they had advanced empirically successful, but from our perspective false, theories. To avoid this objection, de Regt argues that understanding does not require truth, but rather an ability to manipulate and use a theory within a certain domain.

Linking understanding to the idea of comprehending relations or connections immediately raises the question of whether values such as coherence, unity and simplicity are related to the concept of understanding. This link has been explicitly made, with Peter Kosso (2002) arguing that aesthetic values serve as conditions for understanding, and more recently, Angela Breitenbach (2013) arguing that aesthetic values play an epistemic role in science exactly because they aid understanding. According to Breitenbach's account, scientists appeal to aesthetic considerations not because the phenomena themselves instantiate aesthetic properties, but because in aiming to develop simple, unified, elegant theories, scientists develop theories that

\footnotetext{
${ }^{3}$ This account of understanding is not uncontroversial; Kitcher (2002), Lipton (2004), Grimm (2006) and Bird (2007) take understanding to be a kind of knowledge.
} 
provide understanding. This neo-Kantian approach takes aesthetic judgments to be not about objective features of the world, but rather about our own reflections on the objects of our experience. Aesthetic judgments, however, are not taken to be purely subjective, since they demand the agreement of other agents and thus have intersubjective validity. Additionally, as argued in Ivanova (2016), an interesting link between understanding and aesthetic values can be found in Poincaré's take on the aim of science. According to this account, the aim of science is not truth, but rather an understanding of how phenomena are related, and aesthetic values such as simplicity and unity are regulative ideals linked to this ultimate aim of science; they lead to an understanding of the relations that hold between phenomena. For Poincaré, beauty is experienced when one has grasped how different and apparently disconnected phenomena are unified. Poincaré reduces beauty to the simplicity, harmony and unity of theories; he argues that these values persist as ideals of science rather than being subject to time and fashion, and are conditions of thinking. These accounts are instructive in overcoming many of the objections noted above regarding the link between aesthetic values and truth, and in establishing the epistemic role of aesthetic values.

\section{Conclusion}

It remains fascinating that decision-making in science is influenced by aesthetic factors, and it is often maintained that aesthetic values in science have timeless, objective validity. While scientists can be skeptical towards the objective validity of aesthetic judgments, such judgments are persistently employed in practical reasoning. Although the link between beauty and truth is hard to justify, as is the idea that beauty can be predictive of empirical success, it remains an open question why explanations are valued for their aesthetic merit, and why we actively search for symmetry, simplicity, and unity in nature and in our representations of the world.

Bibliography 
Bird, A. (2007) What is Scientific Progress?, Noûs 41: 64-89.

Breitenbach, A. (2013) Aesthetics in Science: A Kantian Proposal. Proceedings of the Aristotelian Society, CXIII: 83-100.

Cellucci, C. (2015) Mathematical Beauty, Understanding, and Discovery. Foundations of Science, 20: 339-355.

Chakravartty, A. (2007), A Metaphysics for Scientific Realism: Knowing the Unobservable. Cambridge: Cambridge University Press.

Chandrasekher, S. (1987) Truth and Beauty: Aesthetics and Motivation in Science. The University of Chicago Press

Cutting, J. (2003) Gustave Caillebotte, French Impressionism, and Mere Exposure. Psychonomic Bulletin \& Review, 10: 319-43.

De Regt, H. (2004) Making Sense of Understanding, Philosophy of Science, 71: 98-109.

De Regt, H. (2015) Scientific understanding: truth or dare? Synthese, 192: 3781 3797.

Dirac, P.A.M. (1980) The excellence of Einstein's theory of gravitation, in M. In M. Goldsmith, A. Mackay, \& J. Woudhuysen (Eds.), Einstein: The first hundred years, Oxford: Pergamon Press.

Duhem, P. (1954[1906]) The Aim and Structure of Physical Theory. Princeton: Princeton University Press.

Dyson, F.J. (1987) Paul Dirac. Obituary Notice, American Philosophical Society Yearbook for 1986, 100-5. 
Elgin, C. (1991) Understanding: Art and Science. Philosophy in the Arts, Midwest Studies in Philosophy (Peter French, Theodore Uehling and Howard Wettstein eds.), Notre Dame: University of Notre Dame Press

Elgin, C. (2009) Is Understanding Factive? In D. Prichard, A. Millar and A. Haddock (eds.) Epistemic value, Oxford: Oxford University Press

Engler, G. (1990) Aesthetics in science and art, British Journal of Aesthetics, 30: 24-33.

Engler, G. (2002) Einstein and the most beautiful theories in physics. International Studies in the Philosophy of Science, 16: 27-37.

French, S. (2014) The Structure of the World: Metaphysics and Representation. Oxford: Oxford University Press.

French, S. (2003) A Model-Theoretic Account of Representation (or, I Don't Know Much About Art...but I Know It Involves Isomorphism). Philosophy of Science, 70: 1472-1483.

Frigg, R. and Hunter M. (eds.) (2010) Beyond Mimesis and Convention. Boston Studies in the Philosophy of Science, Vol. 262.

Friedman, M. (1974) Explanation and scientific understanding. Journal of Philosophy, 71: 5-19.

Gaut, B. and Lopes, D.M. (eds) (2013) The Rautledge Companion to Aesthetics, $3^{\text {rd }}$ ed., Rautledge

Greene, B. (1999) The Elegant Universe. W.W. Norton and Company. 
Grimm, S.R. (2006) Is Understanding a Species of Knowledge? British Journal for Philosophy of Science, 57: 515-535.

Holmes, F. (2001) Stahl, and the Replication of DNA: A History of "The Most Beautiful Experiment in Biology". Yale University Publishing.

Holmes, F. (1996) Beautiful Experiments in the Life Sciences. in A.I.Tauber (ed.) The Elusive Synthesis: Aesthetics and Science, Dordrecht: Kluwer, 83-101.

Kitcher, P. (2002) Scientific Knowledge, in P. Moser (ed.), The Oxford Handbook of Epistemology (New York: Oxford University Press), 385-408.

Lipton, P. (2004) Inference to the Best Explanation, 2nd edition. London: Routledge.

Livingston, P. (2009). Poincaré's delicate sieve: On creativity and constraints in the arts. In Michael Krausz, Denis Dutton, \& Karen Bardsley (Eds.), The idea of creativity, Leiden: Brill.

Ivanova, M. (2010). Pierre Duhem's good sense as a guide to theory choice. Studies in the History and Philosophy of Science, 41: 58-64.

Ivanova, M. (2014) Is There a Place for Epistemic Virtues in Theory Choice?, Virtue Scientia: Bridges Between Virtue Epistemology and Philosophy of Science, Abrol Fairweather (ed.), Synthese Library, Vol. 366, pp. 207-226

Ivanova, M. (2015) Conventionalism About What? Where Duhem and Poincaré Part Ways. Studies in the History and Philosophy of Science, 54: 80-89.

Ivanova, M. (2016, online) Poincaré's aesthetics of science. Synthese [doi:10.1007/s11229-016-1069-1]

Kitcher, P. (1981) Explanatory unification, Philosophy of Science, 48: 507531.

Kivy, P. (1991) Science and Aesthetic Appreciation. Midwest Studies in Philosophy, 26: 180-195.

Peter Kosso (2002) The Omnisienter: Beauty and Scientific Understanding, International Studies in the Philosophy of Science, 16: 39-48. 
Kuhn, T. (1970) The Structure of Scientific Revolutions, Chicago: Chicago University Press

Kuipers, T. (2002) Beauty, A Road to the Truth, Synthese, 131: 291-328.

Mackay and J. Woudhuysen (Eds.), Einstein: The First Hundred Years. Oxford: Pergamon Press, 41-6.

Mach, E. (1984) The Analysis of Sensations and the Relation of the Physical to the Psychical. Trans. by C. M. Williams, La Salle: Open Court.

Meskin, Phelan, Moore and Kieran (2013) Mere Exposure to Bad Art. British Journal of Aesthetics, 53: 139-164.

McAllister (1996) Beauty and Revolution in Science. Ithaca, NY: Cornell University Press.

McAllister, J. W. (2005). Mathematical beauty and the evolution of the standards of mathematical proof. In M. Emmer (Ed.), The visual mind I, 15-34, Cambridge: The MIT Press.

McAllister, J. (1989) Truth and Beauty in Scientific Reasoning. Synthese, Vol. 78: 25-51.

Mizrahi, M. (2012) Idealizations and Scientific Understanding, Philosophical Studies, 160: 237-252.

Montano, U. (2014) Explaining Beauty in Mathematics: An Aesthetic Theory of Mathematics. Synthese Library vol. 370.

O'Malley M.A., Wideman J.G., Ruiz-Trillo I. (2016). Losing complexity: The role of simplification in macroevolution. Trends in Ecology and Evolution, 31: 608-621. 
Parsons, G. and Reuger, A. (2000) The epistemic Significance of Appreciating Experiments Aesthetically. British Journal of Aesthetics, 40: 407-423.

Poincaré (2001) The Value of Science: Essential Writings of Henri Poincaré. ed. Stephen Gould, New York: Modern Library.

Reichenbach, H. (1947). Elements of symbolic logic. New York:Macmillan.

Reuger, A. (1997) Experiments, Nature and Aesthetic Experience in the Eitheenth Century. British Journal of Aesthetics, 37: 305-322.

Strevens, M. (2013) No Understanding Without Explanation, Studies in History and Philosophy of Science, 44: 510-515.

Stump, D. (2007). Pierre Duhem's virtue epistemology. Studies in History and Philosophy of Science, 38, 149-159.

Thuan, T. (2001) Chaos and Harmony: Perspectives on Scientific Revolutions of the Twentieth Century. New York, Oxford University Press.

Toon, A. (2015) Where is the Understanding? Synthese, 192: 3859-3875

Todd, C. S. (2008). Unmasking the truth beneath the beauty. Why the supposed aesthetic judgments made in science may not be aesthetic at all. International Studies in the Philosophy of Science, 22: 61-79.

Van Fraassen, B. (2008) Scientific representation, Oxford: Oxford University Press.

von Neumann, J. (1961). The mathematician. In J. R. Newman (Ed.), The world of mathematics, IV: 2053-2063, New York: Simon \& Schuster.

Watson, J. D. (1968). The double helix: A personal account of the discovery of 
the structure of DNA. London: Weidenfeld and Nicolson.

Zee, A. (1999) Fearful Symmetry: the Search for Beauty in Modern Physics.

Princeton, Princeton University Press

Zeki, S., Romaya J.P., Benincasa, D.M.T., Atiyah M.F. (2014) The Experience of Mathamtical beauty and its Neural Correlates. Frontiers in Human Neuroscience, 8: 1-12. 